\title{
Analysis of China's Real Estate Prices and Macroeconomy Based on Evolutionary Co-spectral Method
}

\author{
Juan $\mathrm{Li}^{1}$, Xuemin Chen ${ }^{2}$ \\ ${ }^{1}$ School of Economics and Management, Beijing Jiaotong University (China) \\ ${ }^{2}$ School of Culture Industries, Beijing Institute of Graphic Communication (China) \\ lijuan@bjtu.edu.cn, chenxm@nankai.edu.cn
}

Received: January 2015

Accepted: March 2015

\section{Abstract:}

Purpose: This paper investigates the dynamic interaction between the real estate market and the macroeconomic environment of China by use of dynamic coherence function based on co-spectral analysis.

Design/methodology/approach: Through a theoretical perspective, the dynamic interrelationship among economic variables at different time intervals (both long and short terms) is analyzed.

Findings: The empirical results show that China's real estate market features a high coherence with the change of the long-term interest rate, employment rate and money supply, while there is a moderate coherence between the real estate market and the inflation rate and economic growth rate, and the coherence between the short-term rate of interest and the real estate market is the lowest.

Research limitations/implications: Previous researches have some shortcomings. They do not consider the dependence between nonlinear series, but the latter is crucial to avoid the deviation of results. In this paper, we proposed a new method of experience to overcome these shortcomings.

Originality/value: The paper provides a reasonable explanation accordingly to different coherences between the real estate market and the macroeconomic variables.

Keywords: real estate, macroeconomy, dynamic coherence function, monetary policy 


\section{Introduction}

The fluctuation in the real estate market not only involves all levels of society and attracts great concerns from the academic circles, policy makers, economic and financial institutions, but also affects the economy and makes the decision-makers feel anxious. China now is in the process of economic growth and urbanization, the real estate market develops very fast and plays a significant role in the national economic development, so having a good knowledge of the interaction between the real estate market and the macro-economy is of great theoretical and practical importance.

It is generally recognized that, both China and the Western countries take price stabilization as the main goal of monetary policy, but fail to avoid asset price bubbles at the same time. The assets price is not only regarded as the information interference source, but also serves as the information shock transmission channel. The housing as collateral for loans has a considerable effect on the value of other financial collaterals. Therefore, it is important to analyze the effect of the monetary policy on the asset price, especially on the real estate.

The real estate market crisis may exert a great influence on the economy, and the housing price crash is a decisive event to many financial crises, so the policy maker shall pay attention to the effect of the real estate market boom and bust on the fluctuations in economic operation. Although the monetary policy affects the housing price significantly, Mishkin (2007) doesn't think the monetary policy should focus too much on the housing price because it is difficult for the Central Bank to identify the real estate bubbles. He suggests that the housing prices for the monetary policy should be limited to their forecast results of inflation and employment.

Many studies try to explain the relationship between the real estate market and the macroeconomy by using a variety of tools, and the macroeconomic factors mostly involve the income, unemployment rate, rate of inflation, population size, and construction cost, etc. Most of the studies come to the conclusion that economic fundamentals provide a good explanation of the fluctuations in the real estate price. Clapp and Carmelo (1994) make a study of three cities of the United States and the results show that the economic fundamentals can well predict the price trend of real estates, and the expected rate of inflation and the unemployment rate have a marked effect. In addition, Capozza, Hendershott and Mack (2002) and Bharat and Zan (2002) also come to the conclusion that the real estate price is mainly affected by the economic fundamentals in the long term. Allen and Carletti (2010) find that the housing price and the macroeconomic environment are in associated movement, and the relatively easy monetary policy is generally found before there is a rise in the price of real estate. Through dynamic stochastic general equilibrium (DSGE) model, Iacoviello and Neri (2010) find out that there is a close relationship between the economic activities of United States and the housing market. 
Based on America's quarterly data from 1959 to 1999, Gauger and Snyder (2003) investigated the long-term relationship between residential investment, interest rates or money supply (M2) and GDP before and after financial deregulation by utilizing cointegration analysis, vector error correction model and impulse response function. They found that before deregulation the short-term interest rate shocks significantly affect residential investment, but after deregulation the long-term interest rate shocks significantly affect residential investment, while residential investment significantly affects GDP. Besides, based on America's quarterly data from 1959 to 2007, Miles (2009) investigated the long-term relationship between residential investment and American economy by VAR. He found that residential investment plays an important role in American economic cycle, especially since the financial deregulation and innovation in 1980, residential investment has promoted both consumption and non-residential investment, and so government's future policies should pay more attention to the impact of residential investment to the economic cycle.

Some other literature studied the relationship between non-economic fundamentals and real estate prices. Non-economic fundamentals focus on the relationship between various control policies such as monetary policies, credit policies, land policies, security-housing policies and tax policies and real estate prices. It showed from Goodhart and Hofmann (2008) studied of 17 developed countries that loose monetary policies led to the rise in real estate prices.

We noted that a lot of existing literature generally studied the relationship between real estate market and macro economy by using empirical models such as VAR model. For example, Bjornland and Jacobsen (2010) studied the interaction between house prices in Norway, Sweden and UK and macroeconomic characteristics by using VAR. They found that unexpected interest rates played a key role in housing price and increase of housing turnover, and almost get instant results, which give prominence to their role as a transmission channel of monetary policies. McCue and Kling (1994) studied USA securitization Real Estate Investment Trust (REITs) market by using non-limiting VAR, and they believed that $60 \%$ of real estate price changes could be explained by macro economic factors. By using FVAR framework, Croux, Forni and Reichlin (2001) found that in South Africa the response of actual price growth to positive monetary shocks is negative and the reaction of housing prices depends on market segmentation. Ling and Naranjo (1997) studied the sensitivity of American commercial real estate returns to macroeconomic risk by using the multi-factor asset-pricing model. The main results show that term structure of interest rates, real per capita consumption growth rate, actual interest rate of treasury bonds and unexpected inflation rate will affect the return on commercial real estates.

Chinese literature on real estate tends to focus on monetary policy, but the results are controversial. By using VAR method, Hui and Ruidong (2013) believed that the main factors for house prices lie in the real estate regulation policies, including land policies, security housing policies and deposit reserve rates. Bin and Qingyun (2011) held that real estate cost shock is the main reason for real estate price fluctuation; at the same time, monetary policies should 
remain relatively moderate. Laifu and Feng (2007) believed that money supply and interest rate shocks have positive effects on China real estate prices by using VAR model.

Previous researches have some shortcomings. For example, it does not consider the dependence between nonlinear series, but the latter is crucial to avoid the deviation of results. Secondly, at least, in theory their methods cannot distinguish short-term and long-term dynamic association between real estate and macro economy. In this paper, we proposed a new method of experience to overcome these shortcomings. Under normal circumstances, spectrum framework is used for analysis of synchronization and dependency of economic cycle and international market.

This paper analyzes the degree and scope of interaction between Chinese real estate market and macroeconomic environment and mainly considers the field of commercial housing. This is because, on the one hand, commercial housing can make a universal influence on asset prices as collateral for loans; on the other hand, the price trends of commercial housing and residential are highly similar (Figure 1 ). We also noted how the dependence of commercial housing on macro economy is essential for return on the investment portfolio. Moreover, commercial housing price is equally important for analysis of economic meaning of public policies. In addition, because China has no real estate fund market currently and the shortterm volatility of stock market is high, this paper does not consider the real estate stock as an agent variable for the study of real estate securitization market.

The research in this paper is based on the dynamic coherence function (DCF) method in spectrum analysis. To the best knowledge of the author, the method is first used to measure the degree of interaction between Chinese real estate market and macro economic variables. DCF method has advantages over ordinary time series methods. It takes into account not only the dynamic dependence between time series; more importantly, this measurement is suitable for non-stable time series.

Therefore, the main contributions of this paper lie in: firstly, we study related patterns for different economic variables by dynamic coherence functions based on co-spectral method, which can identify the convergence properties of synchronization degree of covariance of different variables. To the best knowledge of the author, it is the first time to apply this method to the real estate market. Secondly, in theory, this method can be used to analyze dynamic interaction in different (long and short) time spans. This feature is valuable for portfolio diversification and understanding of conduction mechanism. In addition, it can avoid the deviation caused by VAR model hypothesis. Finally, DCF method used in this paper is very suitable for non-stable time series, we do not need to make any pretreatment on the stability of data so as not to cause any loss of information due to the requirement of data smoothing. 


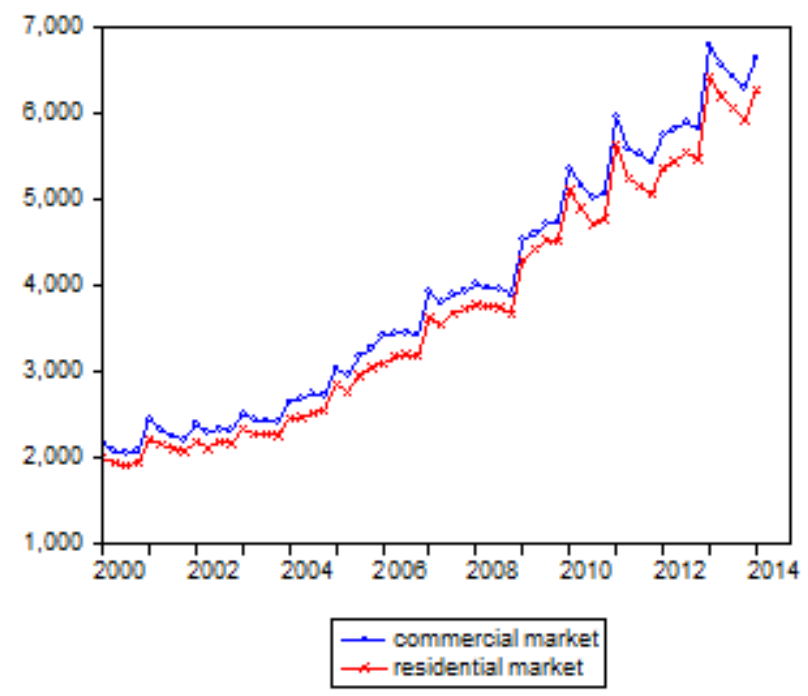

Figure 1. China's Commercial and Residential Housing Prices

\section{Theoretical Model}

The paper adopts the dynamic coherence function used for spectral analysis to measure the dependence of real estate market on the macro-economy, which mainly purports to make allowance for the nonlinear transmission mechanism between the real estate market and the macroeconomic variables. Both the evolutionary co-spectral analysis and the dynamic coherence function (DCF) are briefly described as follows.

The time series method is the most commonly used tool for studying the relevancy between series, provides an instantaneous degree of relevancy between two time series and describes the change of related mode with time. However, there are some weaknesses in the time series method, e.g. it fails to evaluate the change of relevancy of series with time. This limitation can be solved by means of spectral analysis, so as to understand the dependence between series. To be specific, low frequency can be set if long-term characteristics of series need to be observed. And high frequency can be set if short-term ones need to be observed. In this way, the shock response may be evaluated from various time spans.

There are many applications of spectral method in analyzing the interaction between the real estate market and the macroeconomic environment because the spectral method is independent of any non-trend technology and thus avoid the possibility of spurious regression. Second, it helps us apply the coherence function to the non-stationary series. Third, it is capable of identifying the dependence of different time spans of series. In other words, we can use it for observing the dependence degrees of short, medium and long terms. Such identification is very important for the policy makers because they can adjust their decisions according to the economic conditions. 
To analyze the bivariate stochastic process by using the spectral method, Priestley and Tong (1973) expand the evolutionary spectral analysis theory for two-dimensional non-stationary process, and suggest using it for studying the co-variation of two non-stationary series. Ftiti (2010) provides a strict mathematical description of dynamic coherence function (DCF) for the non-stationary process.

Considering a two-dimensional discrete parameter stochastic process $\{X(t), Y(t)\}$ which will be demonstrated in next section, $X(t)$ and $Y(t)$ respectively refer to the corresponding macroeconomic variable and the real estate price growth rate. $X(t)$ and $Y(t)$ can be expressed in the following formula, where $A_{t, x}$ is absolutely integrable,

$$
\begin{aligned}
& X_{t}=\int_{-\infty}^{+\infty} A_{t, X}\left(v_{1}\right) e^{i v t} d Z_{X}\left(v_{1}\right) \\
& Y_{t}=\int_{-\infty}^{+\infty} A_{t, Y}\left(v_{2}\right) e^{i v t} d Z_{Y}\left(v_{2}\right)
\end{aligned}
$$

Where, for each $v, A_{t}(v)$ is time varying and suitable for generalized Fourier transform, and in $[-\pi,+\pi]$ it is an orthogonal process, and $E[d Z(w)]=0$ and $E\left[d Z(w)^{2}\right]=d \mu(w)$, where $\mu(w)$ is a probability measure.

Specifically (refers to Fourier transform),

$$
E\left[d Z_{X}\left(v_{1}\right) d Z_{X}^{*}\left(v_{2}\right)\right]=E\left[d Z_{Y}\left(v_{1}\right) d Z_{Y}^{*}\left(v_{2}\right)\right]=\left[d Z_{X}\left(v_{1}\right) d Z_{Y}^{*}\left(v_{2}\right)\right]=0 .
$$

For $v_{1}=v_{2}, E\left[\left(d Z_{X}\left(v_{1}\right)\right)^{2}\right]=d \mu_{X X}\left(v_{1}\right), E\left[\left(d Z_{Y}\left(v_{1}\right)\right)^{2}\right]=d \mu_{Y Y}\left(v_{1}\right)$ and, $E\left[d Z_{X}\left(v_{1}\right) d Z_{X}^{*}\left(v_{2}\right)\right]=d \mu_{X Y}\left(v_{1}\right)$.

L e t $F_{X}, \quad F_{Y}$ express function families $\left\{\rho_{t, x} \equiv A_{t, X}(v) e^{i v t}\right\},\left\{\rho_{t, Y} \equiv A_{t, X}(v) e^{i v t}\right\}\left\{\rho_{t, X} \equiv A_{t, X}(v) e^{i v t}\right\}$, $\left\{\rho_{t, Y} \equiv A_{t, x}(v) e^{i v t}\right\}$ respectively. Define the evolutionary power cross spectrum at time $t$ as the corresponding function family $F_{X,} F_{Y,}$ and $d H_{t, X Y}$ is

$$
d H_{t, X Y}=A_{t, X} A_{t, Y}^{*} d \mu_{Y Y}(v)
$$

And then, if $\{X(t), Y(t)\}$ is a bivariate stationary process, then $F_{X}$ and $F_{Y}$ can be expressed in a complex exponential function family, i.e., $F_{X} \equiv F_{Y} \equiv\left(e^{i v t}\right)$, and $d H_{t, X Y}$ degrades into the crossspectral classical definition. Therefore, for each $t$, the following formula can be obtained

$$
d H_{t, X Y}=E\left[A_{t, X} d Z_{X}(v) A_{t, Y}^{*} d Z_{Y}^{*}(v)\right]
$$

$d H_{t, X Y}$ is a complex number, and according to Cauchy-Schwarz inequality, the following can be deduced

$$
\left|d H_{t, X Y}\right|^{2} \leq d H_{t, X X} d H_{t, Y Y}, \forall t, v
$$


If the measure $\mu_{r y}(v)$ is absolutely continuous for general Lebesgue measure, $d H_{t, X Y}$ can be expressed in the following equation,

$$
d H_{t, X Y}=h_{t, X Y}(v) d v
$$

S o $h_{t, X Y}(v) d v$ can be called evolutionary cross-spectral density, and $h_{t, X Y}(v)$ describes the relevancy of two stochastic processes at each frequency point. Or,

$$
h(t)=\frac{d H_{t}(v)}{d v},-\pi<v<\pi
$$

Where, $d H_{t}(w)=A_{t}(w)^{2} d \mu(w)$, and the instantaneous variance of $X(t)$ is as follows

$$
\sigma^{2}=\operatorname{var}\left(X_{t}\right)=\int_{-\pi}^{+\pi} h_{t}(w) d(w)
$$

Therefore, for the bivariate process $\{X(t), Y(t)\}$ as described above, each component has an evolutionary spectral density function in the form of formula (1) and (2) of which the timevarying cross spectrum can be directly defined as $H_{t, X Y}$,

$$
H_{t, X Y}=h_{t, X Y}\left(w_{j}, t\right) \exp \left\{i \theta_{X Y}\left(w_{j}, t\right)\right\}
$$

The estimation of dynamic coherence function as described below is partly derived from Ftiti (2010), and the paper considers the discrete process only. According to Priestley and Tong (1973), the evolutionary cross spectral density function can be expressed by the real part and the imaginary part together, i.e.

$$
h_{t, X Y}=C_{t, X Y}-i Q_{t, X Y}(v)
$$

Where, $C_{t, X Y}(v)=R\left\{h_{t, X Y}(v, t)\right\}$ and $Q(v)=I\left\{h_{t, X Y}(v, t)\right\}$ are real-valued functions, and are the evolutionary co-spectrum and quadrature spectrum respectively. If the probability measures $\mu_{x x}(v)$ and $\mu_{r y}(v)$ are absolutely continuous, the evolutionary auto-spectrum density functions $h_{t, x x}(v, t)$ and $h_{t, Y y}(v, t)$ can be defined in a similar way through Ftiti (2010). In this way, the coherence function may be defined as follows

$$
C_{t, X Y}(v)=\frac{\left|h_{t, X Y}(v)\right|}{\left\{h_{t, X X}(v) h_{t, Y Y}(v)\right\}^{1 / 2}}, \quad 0 \leq C_{t, X Y}(v) \leq 1
$$

In fact, the coherence function $C_{t, X Y}(v)$ describes the degree of correlation of two stochastic processes at each frequency, that is to say, it confirms how much output signal $Y(t)$ comes from input signal $X(t)$. If $C_{t, X Y}(v)=1$, it means all output is from the input signal, and is a linear system. If $C_{t, X Y}(v)<1$, then for linear system, it means how much output spectrum $h_{t, Y y}$ at frequency $v$ comes from input spectrum $h_{t, x x}$, and the rest may be from other signal or noise. If $C_{t, X Y}(v)=0$, it means the two signal are completely independent of each other.

The cross- spectral density function is expressed in the following formula:

$$
\hat{h}_{t, X Y}=\sum_{u \in Z} v_{T}(u) \varphi_{X}(v, t-u) \Psi_{Y}(v, t-u)
$$


Where,

$$
\begin{aligned}
& \varphi_{X}(t, v)=\sum_{u \in Z} g(u) X(t-u) e^{i w(t-u)} d u \\
& \Psi_{Y}(t, v)=\sum_{u \in Z} g(u) X(t-u) e^{i w(t-u)} d u
\end{aligned}
$$

Where,

$$
g(u)=\left\{\begin{array}{cc}
\frac{1}{2 \sqrt{h \pi},}, \text { if }|u| \leq h \\
0, & \text { if }|u|>h
\end{array}\right.
$$

The estimation of dynamic time-varying coherence function can be deduced from the estimation of the dynamic cross-spectral density function and the auto-spectral density function of $X(t)$ and $Y(I)$. Therefore, the estimation of dynamic coherence function is as follows,

$$
\operatorname{Coh}_{t, X Y}=\frac{\left|\hat{h}_{t, X Y}(v)\right|}{\left\{\hat{h}_{t, X X}(v) \hat{h}_{t, Y Y}(v)\right\}^{1 / 2}}
$$

\section{Empirical Analysis}

The paper adopts the quarterly data of 2000 to 2014 to estimate the above model. The selection of macroeconomic variables mainly considers the implementation of monetary policy and the economic conditions, and makes allowance for the indicators which are regarded as a significant effect on the real economy by the previous papers, including economic growth rate, inflation rate, interest rate, money supply M2 growth rate, and accession rate. Some papers directly select real estate price and M2 value for studying the relationship between the real estate price and the macroeconomic variables, but this paper employs the real estate price year-on-year growth rate and M2 year-on-year growth rate in empirical calculation after comprehensive consideration.

The paper takes the earning rate of 10-year treasury bonds as the proxy variable of the longterm interest rate, and the 3-month interbank offered rate as the proxy variable of the shortterm interest rate. The above earning rate of 10 -year treasury bonds comes from wind database while other macro-economic quarterly data and real estate data are all from Ceinet database. The real estate price is equal to the commercial housing sales amount divided by the sales area, and its year-on-year growth rate is employed. The inflation rate adopts the CPI year-on-year growth rate; the economic growth rate adopts the GDP year-on-year growth rate, while the accession rate is obtained by dividing the annual newly-increased employment quantity by the total annual employment quantity. We use the Matlab software for empirical calculation. The descriptive statistics of each variable is provided in Table 1 . See Figure 2 for the variation trend of each macroeconomic variable. 
In fact, the GDP growth is an index which may affect the earnings of real estate market and equity securities while the employment growth indicates good economic conditions and consumer behaviors. The long-term interest rate exerts an influence on both the real estate and stock markets through the collateral loan and the present value of expected future cash flow while the short-term rate of interest serves as a wind vane for short-term monetary policy and borrowing cost. The inflation rate is an important purpose of monetary policy, and also a significant component of investor selection and expectation. The money supply influences the real estate market by means of the whole economy. It may have a positive effect on the investment in real estate, but it may cause adverse impacts due to inflation expectation and uncertainty.

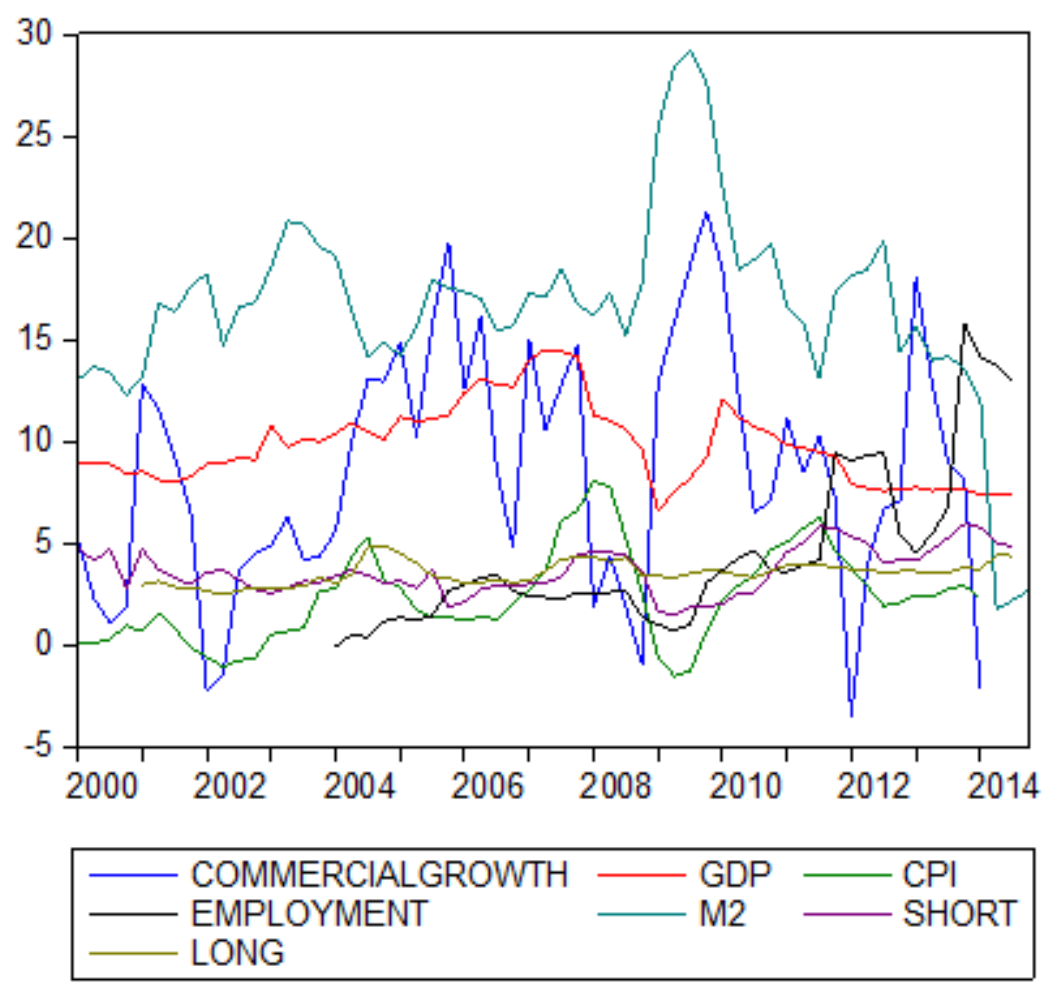

Figure 2. Real Estate Price and Macroeconomic Variable

\begin{tabular}{|c|r|r|r|r|r|r|r|r|r|}
\hline & $\begin{array}{c}\text { Residential } \\
\text { housing } \\
\text { price }\end{array}$ & $\begin{array}{c}\text { Commercial } \\
\text { housing } \\
\text { price }\end{array}$ & $\begin{array}{c}\text { Commercial } \\
\text { house price } \\
\text { growth rate }\end{array}$ & $\begin{array}{c}\text { GDP } \\
\text { growth } \\
\text { rate } \\
(\%)\end{array}$ & $\begin{array}{c}\text { Inflation } \\
\text { rate (\%) }\end{array}$ & $\begin{array}{c}\text { Short-term } \\
\text { interest } \\
\text { rate (\%) }\end{array}$ & $\begin{array}{c}\text { Long-term } \\
\text { interest } \\
\text { rate (\%) }\end{array}$ & $\begin{array}{c}\text { Employment } \\
\text { growth rate } \\
(\%)\end{array}$ & $\begin{array}{c}\text { M2 } \\
\text { growth } \\
\text { rate } \\
(\%)\end{array}$ \\
\hline $\begin{array}{c}\text { Mean } \\
\text { value }\end{array}$ & 3,634 & 3,879 & 2.127 & 9.72 & 2.086 & 3.822 & 3.543 & 4.508 & 4.043 \\
\hline $\begin{array}{c}\text { Median } \\
\text { value }\end{array}$ & 3,199 & 3,460 & 0.399 & 9.3 & 2.033 & 3.663 & 3.569 & 3.164 & 3.932 \\
\hline Maximum & 6,443 & 6,807 & 17.5 & 14.5 & 8.033 & 8.16 & 4.867 & 15.81 & 11.7 \\
\hline Minimum & 1,831 & 2,041 & -6.14 & 6.6 & -2.166 & 1.47 & 2.476 & -0.085 & 0.843 \\
\hline $\begin{array}{c}\text { Standard } \\
\text { deviation }\end{array}$ & 1,473 & 1,546 & 5.833 & 1.957 & 2.388 & 1.373 & 0.558 & 3.974 & 1.69 \\
\hline Skewness & 0.425 & 0.437 & 1.355 & 0.759 & 0.498 & 0.881 & 0.354 & 1.498 & 1.87 \\
\hline Kurtosis & -1.23 & -1.217 & 1.084 & -0.054 & -0.177 & 1.383 & -0.272 & 1.454 & 6.42 \\
\hline
\end{tabular}

Table 1. Descriptive Statistics 
China's real estate market experiences a shorter time, so the paper mainly considers the short-term (semiannual) effect of macroeconomic variables on the real estate market, that is to say, only consider one short-term frequency $\pi$ for bivariate stochastic process, equivalent to two quarters. To be specific, the time span is $\frac{2 \pi}{\lambda}$ of which $\lambda$ refers to frequency. Then, the given frequency is $\pi$, so the defined time span $\frac{2 \pi}{\pi}=2$ quarters, i.e. half a year. If the effect of longer time span needs to be considered, then the frequency may be adjusted, e.g. set $\lambda=\frac{\pi}{10}$ to obtain a 5-year long-term effect.

Figures 3 to 8 report the coherence functions respectively of commercial housing price growth rate and macroeconomic variables.

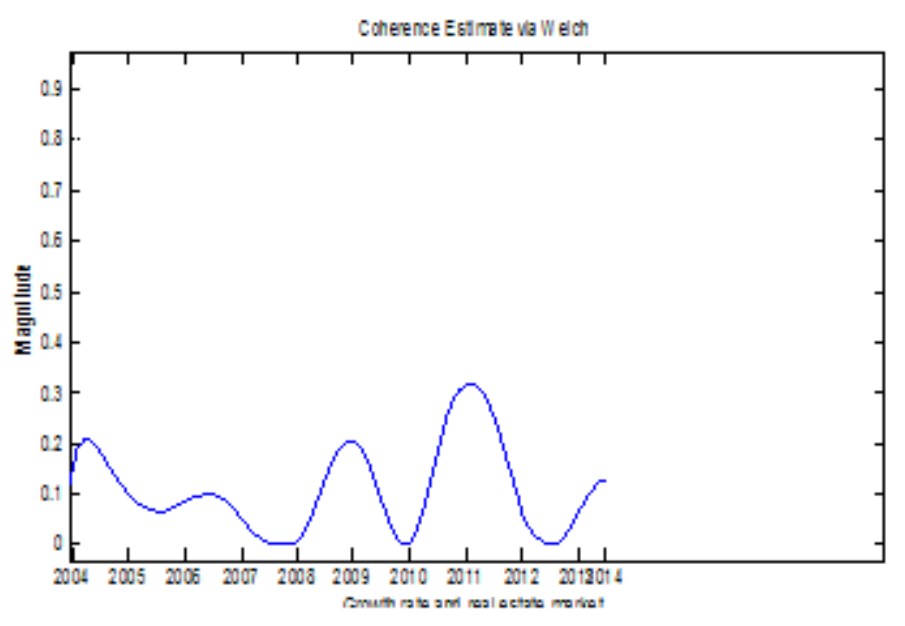

Figure 3. DCF of Economic Growth Rate and Real Estate Market

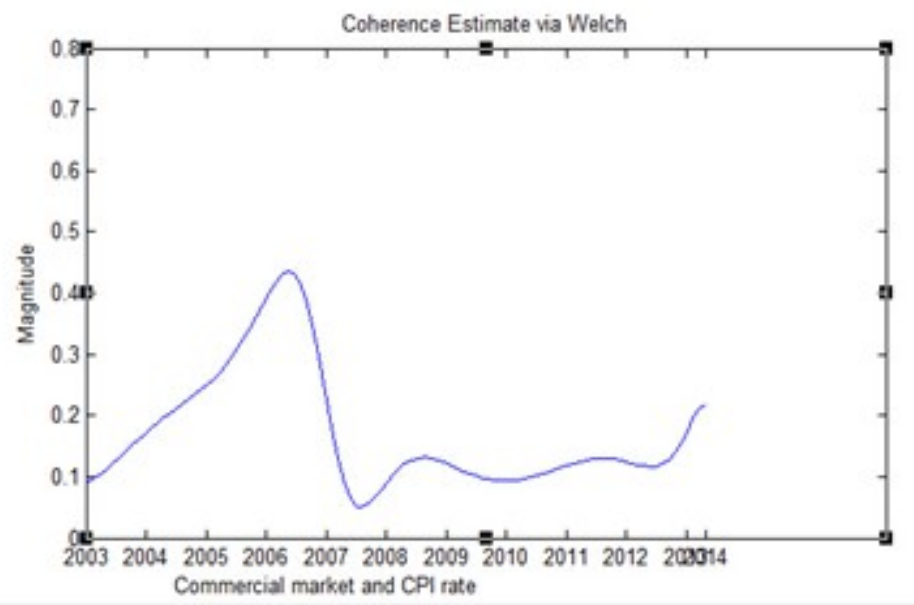

Figure 4. DCF of Inflation Rate and Real Estate Market 


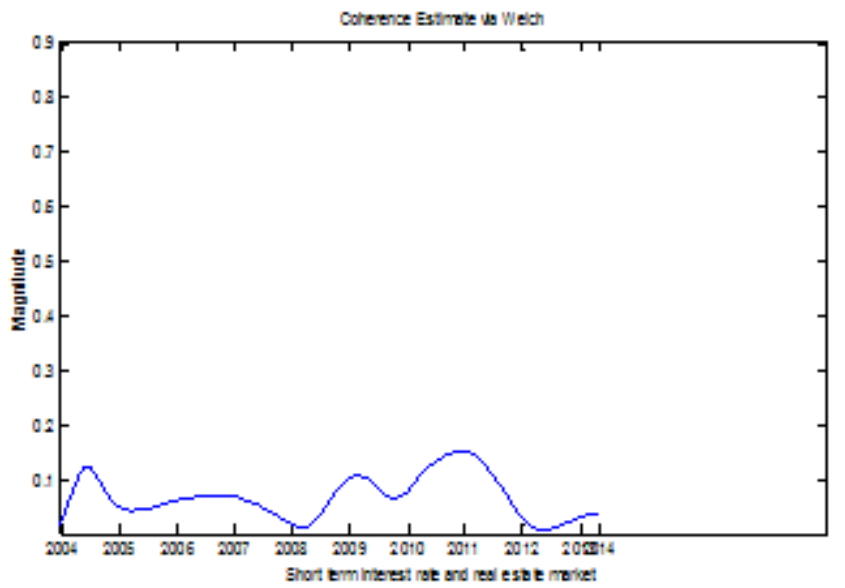

Figure 5. DCF of Short-term Interest Rate and Real Estate Market

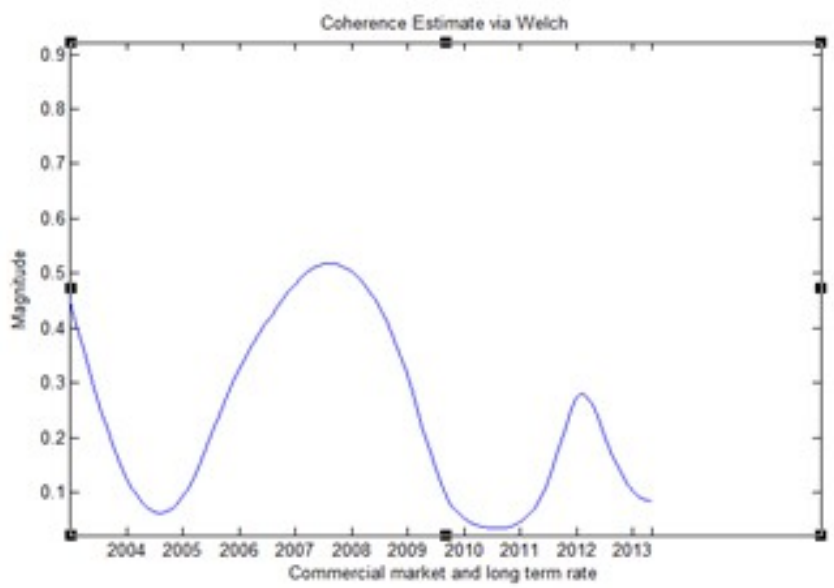

Figure 6. DCF of Long-term Interest Rate and Real Estate Market

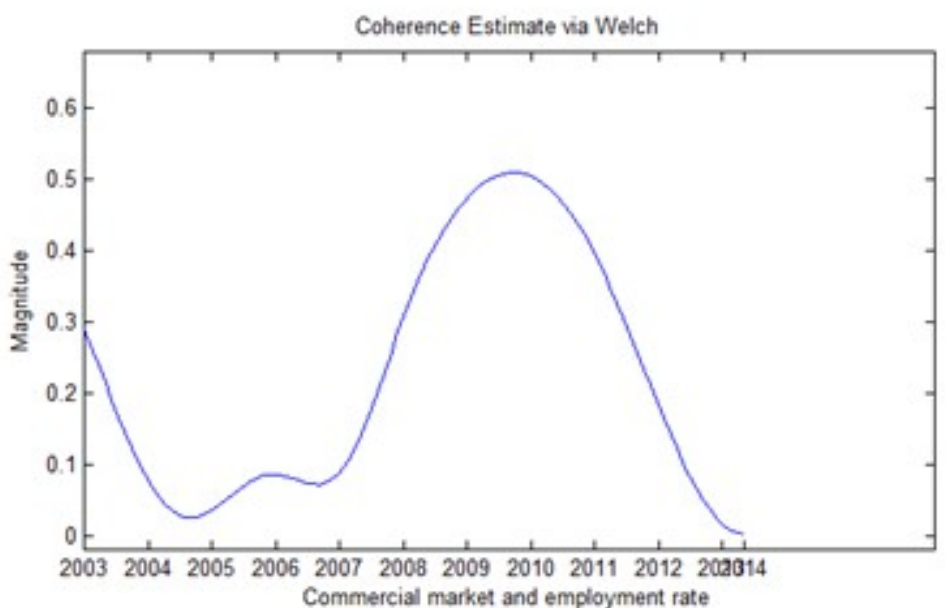

Figure 7. DCF of Employment Rate and Real Estate Market 


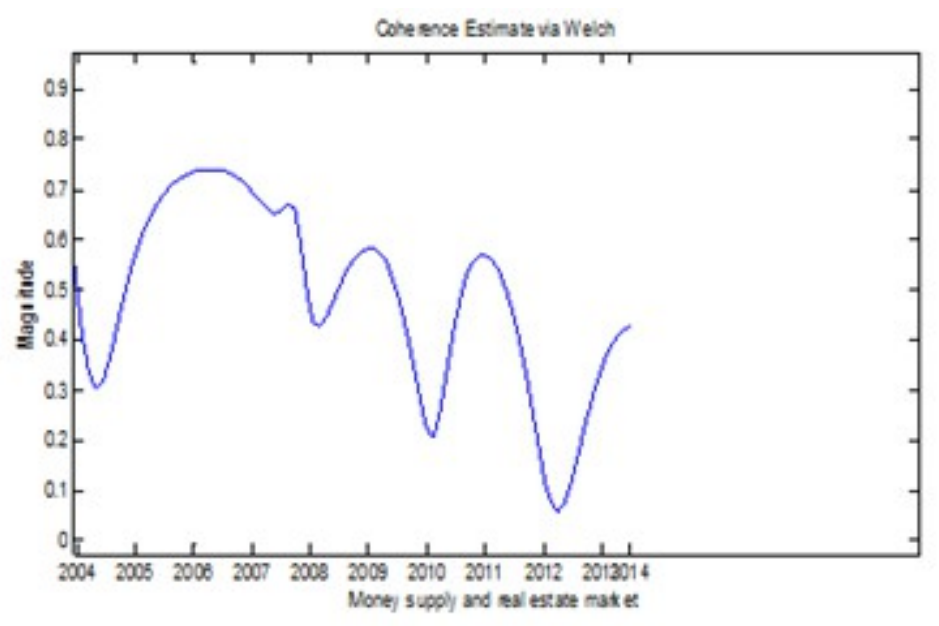

Figure 8. DCF of Money Supply and Real Estate Market

Seen from Figures 3 to 8 , the long-term interest rate, employment rate, money supply and real estate price have a high DCF value, the DCF value of the economic growth rate, inflation rate and real estate price is moderate, while that of short-term interest rate and real estate price is small. The above results are explained as follows.

Change of interest rate can affect real estate prices through direct interest-rate channel and indirect credit channel. Theoretically speaking, on one hand, the transmission of monetary policy is completed through interest rate, so as to affect real estate prices; on the other hand, under the imperfect conditions of financial market, the availability of bank credits plays important role in the transmission process of monetary policy. Interest rate will generate direct influence to the state between supply and demand in the real estate market; high interest rate will lead to increase of costs by fund users and decline of real estate demand, which will further cause decline of real estate investments and real estate prices. Credit channel usually reflects more significant transmission effect of monetary policy in real estate market, housing demand is closely correlated to the asset \& liability status of house-purchasing families, which is reflected in form of down payment requirement, advance payment of transaction expenses and loan repayment ratio. The other reflecting form of credit channel is financial accelerator effect, which means any endogenous change of credit market (such as net asset and pledge) will have increased impact effect on the real estate market.

This paper found through demonstration that the DCF between short-term interest rate and real estate price is relatively low, which means housing prices are not easily affected by fluctuation of short-term interest rate, tendencies of the two are relatively independent. The reliance of real estate market on short-term interest rate is not significant, when attempts are made to prevent real estate bubbles, short-term interest rate is not an important policy tool. The DCF between long-term interest rate and real estate price is different from that of shortterm interest rate, it can be seen from Figure 5 that the long-term one has relatively higher correlation than that of short-term one. The correlation of long-term interest rate had obvious 
increase before 2006 and after 2012, and deviated from the correlation of short-term interest rate. The main cause of deviation between the correlations with the long-term interest rate and short-term interest rate is that the central bank usually could directly adjust short-term interest rate, but has very limited influence on long-term interest rate; long-term interest rate depends on inflation expectation and investors' demand on bonds as well as other factors. Therefore, as for influential factors on real estate prices, long-term interests are more important than short-term interest rate.

Real estate price is considered as one of the channels for monetary policy to influence economy through influencing asset prices; such influence is realized through the family wealth effect for total demand on real estates and direct influence effect on housing expenditures. Figure 7 indicates that real estate market has relatively high correlation between real estate market and employment growth, which means that Chinese real estate market is more sensitive to the factors driving economic growth. Such high-level reliance reflects the importance of employment rate in the implementation of monetary policies, because it is one of the main goals of Chinese monetary policies. When employment rate increases, DCF level is relatively low; while employment rate declines, the DCF level between real estate market and employment growth will be relatively high. This also indicates that during economic downturn, the correlation between real estate market and employment growth is more significant, and reflects that employment growth is an important indicator relating to economic situation. Decline of employment growth has negative influence on purchasing power and consumption, which directly affects economic growth. Employment rate is also a key indicator for house construction activities in the future, house construction determines supply, while employment growth determines demand. Low employment rate means relatively few office space demand and relatively low rent level, then further reflect on the decline of estimated real estate prices. Therefore, relatively low employment growth in fact leads to decline of housing prices. But from the perspective of long-term, higher-level employment growth determines the adjustment of supply and demand of real estate.

It can be seen from Figure 8 that the DCF between real estate market and monetary supply growth rate is at relatively high level and obviously higher than the other economic variables. Chinese monetary policies have always tended to adopt the maintenance of growth of promotion of employment as the main objectives, and haven't paid too much attention on suppression of asset prices. The monetary supply M2 volume in China has always been increasing in recent years, while the investment channels are relatively few compared with that of foreign countries, then the excessive issue of money naturally entered the real estate market, then it's not difficult to understand the high DCF value between housing price and real monetary supply. Although M2 is indeed an important variable to affect housing prices, but another fact worth to be noted that after 2009, the DCF between housing price and monetary supply had the trend of decline. The most important factor that broke the correlation between M2 and housing prices should be the change of house-purchasing behaviors, which depended 
on two points: first, the change of Chinese population structure. With the increase of aging, the rigid demand for housing is declining; housing prices are growing at slower rate, so the investments in real estate are cooling down. Second, household registration system reform. With the development of urbanization, house-purchasing behaviors consumers will be determined by work location or other factors, then the housing prices in different places will also have structural changes.

Generally speaking, the key factors that affect economic growth also include capital and total factor productivity besides the foresaid labors. It can be seen from Figure 3 that compared with long-term interest rate, employment rate and monetary supply growth rate, the DCF between economic growth rate and housing price is not very high. However, long-term interest rate level, monetary supply and employment rate will to certain extent be reflected in economic growth indicators; thus, the result of Figure 3 may imply that if deducting the foresaid factors, then the DCF between economic growth and real estate price may be even lower. Housing price has negative influence on total factor productivity, the core influence of housing price on national economy is the direct redistribution of resources, while high housing prices in long term will severely affect the efficiency of resource redistribution, which is not only reflected among enterprises, but also reflected in the entering and quitting mechanism. As for the entire society and for enterprises, the objective is not total factor productivity and efficiency, but profit; in this way, the continuous and excessively fast housing price increase will allocate resources to real estate and other industries relating to real estate, such structural distortion will cause profit rate and total factor productivity to be upside down.

Reallocation of Chinese resources is very important to economic growth, but such a positive effect has begun to decline since 2004. The rapid rise in housing prices may not be so favorable to growth. We are now faced with another round of housing prices and Chinese housing prices began to change, in which case local government is relatively an incentive and hopes to be able to maintain or even continue the rise in housing prices. However, if prices fall quickly, all national practices and theories tell us that the presentation of financial accelerator effect may also be very dangerous for the whole Chinese economy. For the entire real estate market, too fast price rise or fall is not good. For the whole macro economy, it is an important and difficult problem to build a healthy real estate market for Chinese macro economic development.

Figure 4 shows the degree of dynamic interaction between real estate price and inflation rate. In 2006, DCF of housing prices and inflation rate (CPI) was very high, and then dropped gradually and maintained at a relatively stable level. Industrial material prices will affect the real estate market, while real estate development includes reinforcing steel, cement, concrete, bricks, glass and other raw materials. The rise in real estate prices must pull demand for raw materials and lead to the rise in prices of raw materials. For example, the market price of steel will rise with the increase in demand of reinforcing steel (from real estate), and then all iron and steel related commodity prices will tend to rise, which chain reaction can lead to similar 
metal commodity prices follow up. Similarly, relevant steel-making coke prices will rise, and the cost for coal related industries such as thermal power generation will increase, so it is possible for consumers to pay more electricity fee. Therefore, we can see the high coherence between inflation and real estate market. However, the factors for inflation are perplexing. Although real estate price is highly associated with inflation, after all, inflation is only a factor for price, and we cannot say that there exists a decisive effect between them. In fact, in the past 10 years, price rise in many Chinese areas has far exceeded inflation and wage growth.

\section{Conclusions}

The previous papers lack common understanding on the relationship between the real estate and macro economy, so this paper further studies the dynamic interaction between China's macro-economic environment and the real estate market. This paper merely considers the short-term interaction between the two due to a short time of Chinese real estate market, but the model of this paper also applies to the long-term interaction between the macroeconomic variable and the real estate market.

The covariant movement between real estate market and macro economy reveals the contact between the two. In fact, Chinese real estate market has relatively high correlation between the change of long-term interest rate, employment rate and monetary supply, while the correlation between inflation rate, economic growth rate and real estate market is on medium level, and the correlation between short-term interest rate and real estate market is the lowest.

We found that the main reason of the deviation of correlation between long-term interest rate and short-term interest rate is that the central bank usually could directly control short-term interest rate, but has very limited influence on long-term interest rate; long-term interest rate depends on inflation expectation and investors' demand on bonds as well as other factors. For the influential factors of real estate prices, long-term interest rate is more important than short-term interest rate. Besides, although M2 is indeed a very important variable to affect housing prices, but the DCF between housing price and monetary supply tends to decline, so the most important factor to break the correlation between $M 2$ and housing price should be the change of house-purchasing behaviors. Actual income is a main driving force to real estate prices, which reflects the transmission effect of wealth to real estate market. In fact, declining employment rate has negative influence on actual income, and reduces purchasing power and house affording ability, which means the decline of the house price-income ratio. Therefore, relatively less expenditure on housing market will occur. On the other hand, decline of employment growth will generate a relatively low actual income, then further reduces family wealth. It reduces the value of pledge and further reduces the receiving of mortgage loan value. According to our research, its DCF has relatively high value, which indicates that such wealth effect plays an important role. 
If we rule out the influence of long-term interest rate level, monetary supply and employment rate in economic growth indicators, then the DCF between economic growth and real estate price could be even lower. High housing prices in long-term will severely affect the efficiency of resource redistribution, and will cause the profit rate and total factor productivity to be upside down. Inflation and real estate market has correlation in medium level, but the factors causing inflation are very complex, so there's no determinant relationship between the two.

Although this paper didn't consider the securities market, such as using real estate-type stock as the proxy variable of the American Real Estate Investment Trusts (REITs), because the short-term fluctuation of securities market is high. However, even the structural methods of indexes are different, the overall trend of different real estate indicators are the same. We believe that there's a common trend to drive all the real estate markets, but of course the returns of different real estate markets are different.

For further research, on one hand, we could consider the comparison of dynamic interaction between real estate market and macro economy in foreign countries, such as the US, UK and India. Because the US represents big developed economies, UK represents small developed economies, while India represents big developing economies. On the other hand, many different real estate markets in China could be considered, such as the securities market.

\section{References}

Allen, F., \& Carletti, E. (2010). What should central banks do about real estate prices?. Working Paper No. 11-29. Wharton Financial Institutions Center, University of Pennsylvania. November.

Bharat, B., \& Zan, Y. (2002). House Prices and Housing Investment in Sweden and the United Kingom: Econometric Analysis for the Period 1970-1998[J]. Review of Urban and Regional Development Studies, 14(2), 189-216. http://dx.doi.org/10.1111/1467-940X.00054

Bin, L., \& Qingyun, L. (2011). Analysis of China's real estate price fluctuation and monetary policy. Economic Science(China), 3, 18-32.

Bjornland, H., \& Jacobsen, D. (2010). The role of house prices in the monetary policy transmission mechanism in small open economies. Journal of Financial Stability, 6, 218-229. http://dx.doi.org/10.1016/j.jfs.2010.02.001

Capozza, D.R., \& Hendershott, P.H., \& Mack, C. (2002). Determinants of Real House Price Dynamics. NBER Working Paper, No.9262.

Clapp, J., \& Carmelo G. (1994). The Influence of Economic Variables on Local House Price Dynamics. Journal of Urban Economics, 36(2), 161-183. http://dx.doi.org/10.1006/juec.1994.1031

Croux, C., Forni, M., \& Reichlin, L. (2001). A measure of comovement for economic variables: theory and empirics. The Review of Economics and Statistics, 83, 232-241. 
Ftiti, Z. (2010). The macroeconomic performance of the inflation targeting policy: an approach based on the evolutionary co-spectral analysis (extension for the case of a multivariate process). Economic Modelling, 27, 468-476. http://dx.doi.org/10.1016/j.econmod.2009.10.013

Gauger, J., \& Snyder, T. (2003). Residential Fixed Investment and the Macroeconomy: Has Deregulation Altered Key Relationships. Journal of Real Estate Finance and Economics, 27(3), 335-354. http://dx.doi.org/10.1023/A:1025842108205

Goodhart, C., \& Hofmann, B. (2008). House Prices, Money, Credit and the Macroeconomy. ECB Working Paper NO88. http://dx.doi.org/10.1093/oxrep/grn009

Hui, A., \& Ruidong, W. (2013). Empirical analysis of Chinese real estate price influencing factors. Finance Economics(China), 3, 115-124.

Iacoviello, M., \& Neri, S. (2010). Housing market spillovers: evidence from an estimated DSGE model. American Economic Journal: Macroeconomics, 2, 125-164.

http://dx.doi.org/10.1257/mac.2.2.125

Laifu, W., \& Feng, G. (2007). Study on the dynamic effect of monetary policy on real estate price. Studies of Finance and Economics(China), 11, 15-19.

Ling, D., \& Naranjo, A. (1997). Economic risk factors and commercial real estate returns. The Journal of Real Estate Finance and Economics, 14, 283-307.

http://dx.doi.org/10.1023/A:1007754312084

McCue, T., \& Kling, J. (1994). Real estate returns and the macroeconomy: some empirical evidence from real estate investment trust data, 1972-1991. Journal of Real Estate Research, 9, 277-287.

Miles, W. (2009). Housing Investment and the U.S. Economy: How Have the Relationships Changed. The Journal of Real Estate Research, 31(3), 329-350.

Mishkin, F.S. (2007). Housing and the monetary transmission mechanism. Working Paper No. 13518. National Bureau of Economic Research. October.

Priestley, M., \& Tong, H. (1973). On the analysis of bivariate non-stationary processes. Journal of the Royal Statistical Society Series, 35, 153-166.

Journal of Industrial Engineering and Management, 2015 (www.jiem.org)

\section{(2)}

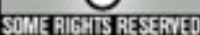

Article's contents are provided on a Attribution-Non Commercial 3.0 Creative commons license. Readers are allowed to copy, distribute and communicate article's contents, provided the author's and Journal of Industrial Engineering and Management's names are included. It must not be used for commercial purposes. To see the complete license contents, please visit http://creativecommons.org/licenses/by-nc/3.0/. 